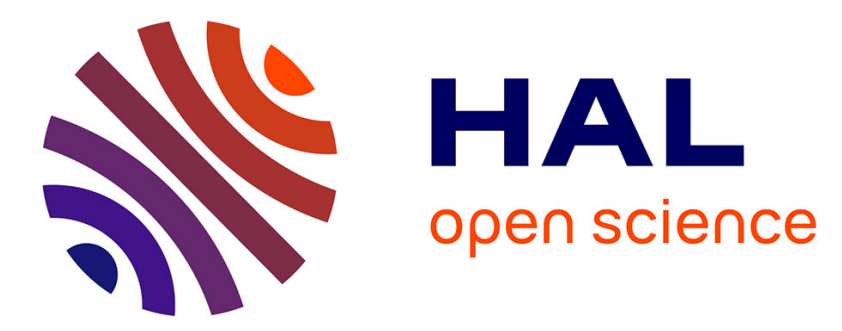

\title{
Quantitative determination of the solidus line in the dilute limit of succinonitrile-camphor alloys
}

F.L. Mota, L.M. Fabietti, N. Bergeon, L.L. Strutzenberg, A. Karma, B. Billia, R. Trivedi

\section{- To cite this version:}

F.L. Mota, L.M. Fabietti, N. Bergeon, L.L. Strutzenberg, A. Karma, et al.. Quantitative determination of the solidus line in the dilute limit of succinonitrile-camphor alloys. Journal of Crystal Growth, 2016, 447, pp.31-35. 10.1016/j.jcrysgro.2016.04.054 . hal-01637148

\section{HAL Id: hal-01637148 https://hal.science/hal-01637148}

Submitted on 28 Oct 2019

HAL is a multi-disciplinary open access archive for the deposit and dissemination of scientific research documents, whether they are published or not. The documents may come from teaching and research institutions in France or abroad, or from public or private research centers.
L'archive ouverte pluridisciplinaire HAL, est destinée au dépôt et à la diffusion de documents scientifiques de niveau recherche, publiés ou non, émanant des établissements d'enseignement et de recherche français ou étrangers, des laboratoires publics ou privés. 


\section{Author's Accepted Manuscript}

Quantitative determination of the solidus line in the dilute limit of succinonitrile-camphor alloys

F.L. Mota, L.M. Fabietti, N. Bergeon, L.L. Strutzenberg, A. Karma, B. Billia, R. Trivedi

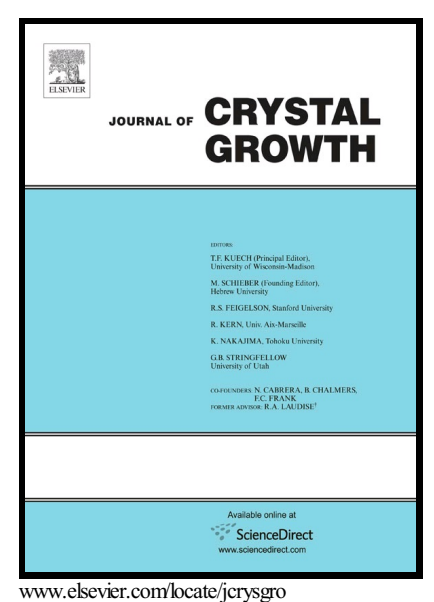

PII: $\quad$ S0022-0248(16)30200-7

DOI: $\quad$ http://dx.doi.org/10.1016/j.jcrysgro.2016.04.054

Reference: CRYS23326

To appear in: Journal of Crystal Growth

Received date: 23 March 2016

Revised date: 21 April 2016

Accepted date: 25 April 2016

Cite this article as: F.L. Mota, L.M. Fabietti, N. Bergeon, L.L. Strutzenberg, A Karma, B. Billia and R. Trivedi, Quantitative determination of the solidus line is the dilute limit of succinonitrile-camphor alloys, Journal of Crystal Growth http://dx.doi.org/10.1016/j.jcrysgro.2016.04.054

This is a PDF file of an unedited manuscript that has been accepted fo publication. As a service to our customers we are providing this early version o the manuscript. The manuscript will undergo copyediting, typesetting, an review of the resulting galley proof before it is published in its final citable form Please note that during the production process errors may be discovered whic could affect the content, and all legal disclaimers that apply to the journal pertain 


\title{
ACCEPTED MANUSCRIPT
}

\section{Quantitative determination of the solidus line in the dilute limit of succinonitrile-camphor alloys}

\author{
F.L. Mota ${ }^{a, b^{*}}$, L.M. Fabietti ${ }^{c}$, N. Bergeon ${ }^{a}$, L.L. Strutzenberg ${ }^{d}$, A. Karma ${ }^{e}$, B. Billia ${ }^{a}$, R. \\ Trived $i^{b}$ \\ ${ }^{a}$ Institut Matériaux Microélectronique Nanosciences de Provence, Aix-Marseille Université and CNRS UMR \\ 7334, Campus Saint-Jérôme, Case 142, 13397 Marseille Cedex 20, France \\ ${ }^{\mathrm{b}}$ Department of Materials Science and Engineering, Iowa State University, Ames, Iowa 50010, USA \\ ${ }^{\mathrm{c}}$ Facultad de Matematica Astronomia y Fisica, Universidad Nacional de Cordoba and Instituto de Fisica \\ Enrique Gaviola, CONICET, Argentina \\ ${ }^{\mathrm{d}}$ Marshall Space Flight Center, Huntsville, AL 35812 USA \\ ${ }^{\mathrm{e}}$ Department of Physics and Center for Interdisciplinary Research on Complex Systems, Northeastern \\ University, Boston, Massachusetts 02115, USA
}

\begin{abstract}
Different phase diagram measurements for succinonitrile-camphor alloys to date have yielded different values of the solute partition coefficient and the freezing range of the alloy. These parameters are critical to model solidification microstructure evolution. New measurements are made to precisely characterize the dilute limit of the succinonitrile-camphor phase diagram using thin-sample directional solidification experiments where convection is negligible, so that solute transport in the melt is purely diffusive, and the temperature gradient is constant in time. These results are confirmed through complementary measurements by differential scanning calorimetry and isothermal annealing. Possible measurement uncertainties in previously measured solidus lines are discussed. Experimental results were further confirmed using a boundary layer model of transient planar interface dynamics.
\end{abstract}

Keywords: A1, phase diagrams; B1, succinonitrile-camphor; A1, directional solidification; A1, isothermal heat treatments; $\mathrm{A} 1$, differential scanning calorimetry

*corresponding author: fatima.lisboa-mota@im2np.fr 


\section{ACCEPTED MANUSCRIPT}

\section{Introduction}

In many solidification processes, it is critical to determine how microstructures are affected by different growth conditions so that processing parameters can be designed to tailor microstructures with optimum properties [1]. Before the development of synchrotron X-ray imaging [2], the opacity of metallic alloys has prevented in situ visualization during solidification so that transparent organic model systems that freeze like metals have been used to explore the dynamical evolution of the solid-liquid interface morphology [3-6]. For example, the dynamical formation of three-dimensional arrays of cells/dendrites under diffusive growth conditions was recently characterized during solidification of a succinonitrile (SCN)- 0.24 wt\% camphor alloy under microgravity in the Device for the Study of Critical Liquids and Crystallization (DECLIC) [7]. Although these experiments provided valuable benchmark data, their analysis requires precise knowledge of physical properties and system parameters. During the analysis of the initial planar front transient behavior [8], a dilemma was faced since several versions of the phase diagram exist in the literature [9-14]. Specifically, the uncertainty in the solidus line, and thus on the solute partition coefficient $k$, was found to be critical since it strongly influences the quantitative predictions of the initial planar front transient as well as the subsequent development of solidification microstructures.

Different studies on SCN-camphor phase diagram [10,11,14] agree on the liquidus line and the eutectic temperature $\left(T_{E}\right)$. However, significant differences exist on the solidus line. Teng and Liu (TL) [11] measured steady-state planar interface temperature during directional solidification, which is taken as the solidus temperature $\left(T_{s}\right)$. Witusiewicz et al. (WHR) [14] measured the volume fractions of solid and liquid under different isothermal conditions so that the solidus line could be determined by using the lever rule and assuming thermodynamic equilibrium, as shown by Mota et al.[8]. These two methods should in principle give identical results, but significant differences were observed, as shown in Figure 1. At the eutectic tieline, TL [11] obtained a $k$ value of 0.3 , while WHR [14] data gave 0.013. The aim of this paper is to resolve this discrepancy in $k$ values through critical assessment of 


\section{ACCEPTED MANUSCRIPT}

possible sources of errors in previous measurements, and to present reliable experimental results on the solidus line in the SCN-camphor system in the dilute limit.

The measured planar interface temperature at steady-state growth will correspond to the solidus temperature $T_{s}$ of the alloy only if local equilibrium conditions at the interface are satisfied and the growth is controlled by diffusion. The presence of local equilibrium at the interface can be examined by measuring steady-state planar interface temperature as a function of velocity, which will be a function of velocity if kinetic effects are present at the interface [15]. Several experimental studies have shown that interface kinetics effects are negligible in pure and dilute alloys of succinonitrile. Thus, one needs to ensure that no convection effects are present in the liquid during growth. TL [11] carried out directional solidification experiments by using the horizontal growth technique in which the gravity vector is perpendicular to the growth direction of the solid-liquid interface so that there is no threshold for convection. In this case convection will always be present, but it can be made negligible by using higher growth rates or thinner samples. Since very low velocity is required for stable planar front growth, it is important to first check if the sample thickness is sufficiently small to suppress convection. In order to examine the possibility of convection in their experiments we consider the order of magnitude analysis of Camel and Favier [16, 17]. They analyzed the horizontal solidification case and identified the regimes of convection and diffusion on a plot (Fig.2) of the Grashof-Schmidt number, $G r S c=\beta_{T} g G R^{4} / v D_{L}$, characteristic of convection, versus the Peclet number, $P e=V R / D_{L}$, characteristic of solidification. $V$ is the pulling velocity, $D_{L}$ the diffusion coefficient in the liquid $\left(270 \mu \mathrm{m}^{2} / \mathrm{s}\right.$ [11]), $R$ the characteristic length scale equal to the smallest sample dimension [18], $\beta_{\mathrm{T}}$ the thermal expansion coefficient $\left(7.85 \times 10^{-4}{ }^{\circ} \mathrm{C}^{-1}[19]\right), g$ the magnitude of gravity vector, $G$ the thermal gradient, and $v$ the kinematic viscosity $\left(2.6 \mathrm{~mm}^{2} / \mathrm{s}[20]\right)$. When the experimental conditions used by TL [11] for $R=200 \mu \mathrm{m}$ are plotted in Fig. 2, the representative points fall in the domain where solute transport in the melt is dominated by fluid flow, in which case the planar interface temperatures are predicted to deviate from the solidus temperature. We shall 


\section{ACCEPTED MANUSCRIPT}

thus carry out experiments in thinner samples, $R=100 \mu \mathrm{m}$, under growth conditions that predict diffusive growth in Fig.2, and determine the solidus temperature $T_{s}$ for different compositions.

Measurement of the equilibrium volume fractions of solid and liquid in isothermal annealing experiments should allow the determination of the solidus line if: (i) the annealing treatment is carried out for sufficient time to reach thermodynamic equilibrium since diffusion in the solid is slow, and (ii) the measurement of the liquid fraction requires the knowledge of the shape of the liquid in three-dimensions. The liquid fraction determined from the top observation in a transparent system only gives the projection of the liquid region. We shall thus carry out isothermal annealing experiments and show that both these requirements are not met in the results presented by WHR [14].

\section{Experimental procedure}

The SCN was purified by distillation under vacuum followed by multiple passes of zone refining [21]. The purity was characterized by the freezing range of the purified material, which was measured as $3 \mathrm{mK}$, and it corresponds to a purity of $99.9998 \%$. Camphor was sublimated under vacuum from the $98 \%$ commercial product. Alloys within the composition range 0 - $6 \mathrm{wt} \%$ camphor, as well as eutectic (23.6 wt\% camphor), were prepared inside the glovebox under high-purity nitrogen atmosphere. Nitrogen atmosphere was preferred rather than argon because previous studies already show that the addition of argon provides a simple, controllable dilute solute with succinonitrile $[13,22]$.

For directional solidification experiments, the sample thickness should be smaller than $200 \mu \mathrm{m}$ to reduce significantly the convection effects, but larger than $50 \mu \mathrm{m}$ to avoid a curved interface in the direction of the thickness because of the contact angle effect at the wall-interface junction [18, $23,24]$. We thus used $100 \mu \mathrm{m}$ thick samples, and selected pulling rates and thermal gradient values that gave stable planar front growth for each solute concentration. Also, the velocity and thermal 


\section{ACCEPTED MANUSCRIPT}

gradient values were selected such that they were in the diffusive regime in Figure 2 for $100 \mu \mathrm{m}$ thick samples. The samples were first stabilized in a thermal gradient and then directionally solidified for a long time until the presence of steady-state growth was established. The evolution of interface position with time was measured and the interface temperature was determined from its position by interpolation between pure SCN and eutectic alloy samples that were solidified in the same experiment.

For isothermal annealing experiments, inside the glovebox under the protection of high-purity nitrogen, samples were filled in thin $12.5 \mu \mathrm{m}$ glass cuvettes, solidified fast and hermetically closed. The device used to keep isothermal conditions was a brass block with a torturous duct inside for silicon oil (or water) to flow through. The oil temperature was controlled by a thermal bath. A calibrated K-type thermocouple was used to measure the sample temperature. The samples were first completely melted, solidified quickly and then equilibrated at a temperature slightly above the eutectic temperature for long periods of time. The microstructures were observed in situ and phase fractions were evaluated from photos taken during isothermal annealing.

For differential scanning calorimetry (DSC) experiments realized in a Perkin-Elmer Pyris 1, approximately $20 \mathrm{mg}$ of liquid alloy (melted and homogenized inside the glovebox under the protection of pure nitrogen) was transferred into an aluminum crucible, which was then sealed. Samples were heated and cooled at $5{ }^{\circ} \mathrm{C} / \mathrm{min}$ under nitrogen while using an empty crucible as reference. To ascertain the precision of the instrument, a gallium standard and pure SCN were used. The solidus temperatures are obtained within $\pm 0.1^{\circ} \mathrm{C}$ by taking the slope of the primary phase peak at the inflection point and extrapolating to the heat flow baseline.

\section{Results and Discussion}

Directional solidification experiments were carried out with different pulling rates in $0.24,0.5$ and 0.9 wt\% camphor alloys. Pulling rates between 0.3 and $0.5 \mu \mathrm{m} / \mathrm{s}$, and thermal gradient between 


\section{ACCEPTED MANUSCRIPT}

6.0 and $10{ }^{\circ} \mathrm{C} / \mathrm{mm}$ were used since Camel-Favier analysis shows that these conditions are expected to give diffusive growth for $100 \mu \mathrm{m}$ thick samples (Fig. 2). The variations in interface temperature with time for these compositions are shown in Figure 3. Solidification was carried out for long time $(80 \mathrm{hr})$ to ensure that a plateau was observed for a period of about $33 \mathrm{hr}$ so that the growth is likely governed by diffusion. The measured solidus temperature $T_{s}$ for the three compositions are shown in Figure 1, and they are below the planar front temperatures measured by TL [11]. The higher temperatures measured by TL indicate possible presence of convection.

Convection effects in $100 \mu \mathrm{m}$ thick samples can also become important if the pulling velocity is reduced. Directional solidification experiments were thus carried out in $100 \mu \mathrm{m}$ thick samples in 0.5 , 0.9 and $1.1 \mathrm{wt} \%$ camphor at a lower velocity of $\mathrm{V}=0.1 \mu \mathrm{m} / \mathrm{s}$. The interface temperature was measured over one week and the interface was found to drift significantly and did not reach steadystate condition. These results on interface temperature variation with time for $0.5 \mathrm{wt} \%$ camphor are shown in Figure 4, where the results for diffusive growth at $V=0.3 \mu \mathrm{m} / \mathrm{s}$ are also shown for comparison. The presence of convection at this small velocity of $0.1 \mu \mathrm{m} / \mathrm{s}$ is also predicted by the Camel and Favier diagram $[16,17]$. Note that the interface temperature under convective condition is higher than that under diffusive growth conditions.

We now analyze the results on planar front dynamics obtained in the present work by using the Warren-Langer (WL) model for diffusive growth [25], as well as the boundary layer model of Karma et al. (KRFT) [26] that describes the effect of convection on planar front transient. The KRFT model incorporates the effect of convection by assuming that solute diffusion only takes place within a boundary layer of fixed thickness $\delta$, with a melt of spatially uniform composition outside this boundary layer. The composition in the solid $C_{\mathrm{s}}$ is governed by $\Delta=\delta \mathrm{V} / \mathrm{D}_{\mathrm{L}}$. The diffusive $\mathrm{WL}$ model is simply the limiting case of the KRFT model when the hydrodynamic boundary layer $\delta$ is much larger than the diffusion layer $\left(D_{L} / V\right)$. When convection effects are present, the limit of the KRFT model for long samples corresponds to the well-known segregation equation developed by Burton, Prim and 


\section{ACCEPTED MANUSCRIPT}

Slichter (BPS) [27] in which steady-state growth is considered. In these conditions, the melt composition outside the boundary layer is considered to be equal to the alloy composition, $\mathrm{C}_{0}$, for long samples or for conditions where the effects of convection are negligible. The limiting case of diffusive growth occurs when $\Delta \rightarrow \infty$ where $\mathrm{C}_{\mathrm{s}}=\mathrm{C}_{0}$, and of complete mixing in the liquid occurs when $\Delta \rightarrow 0$ where $\mathrm{C}_{\mathrm{s}}=\mathrm{kC}_{0}$. A systematic study was carried out to calculate the composition in the solid $\mathrm{C}_{\mathrm{s}}$ as a function of $\Delta$ by using the KRFT model [26], and the effects of convection became negligible for $\Delta \geq 7$. The same values of $\Delta$ can be obtained by using the BPS equation for large samples [27]. $\begin{array}{llll}\text { Considering the liquidus equation } & \text { well-established equats }\end{array}$ $T_{L}=58.08-1.3825 C_{L}+0.0363 C_{L}^{2}-6.10 \times 10^{-4} C_{L}^{3}$ [11], where $T_{L}$ is the liquidus temperature and $C_{L}$ is the composition in the liquid, and the presently determined solidus temperatures, the solute distribution coefficients $k$ are obtained as: $0.07 \pm 0.01,0.09 \pm 0.01$, and $0.12 \pm 0.01$ for compositions $0.24,0.5$ and 0.9 wt\% camphor, respectively. We now compare our experimental results with the KRFT model [26] in Figure 3 a for values of $\Delta>7$ for all compositions $(0.24,0.5$ and 0.9 wt\%) and an excellent quantitative agreement is found. The obtained results are the same using the WL model of diffusive growth $(\Delta \rightarrow \infty)$, which highlights that our results are under diffusive growth conditions. The KRFT model was also applied to study the results obtained at $V=0.1 \mu \mathrm{m} / \mathrm{s}$ and in Figure 4 it can be seen that there is an excellent quantitative agreement between experimental and model results by using $\Delta=2$ which is the indication that significant convection effects were present.

We now consider the solidus temperature values obtained by TL [11] that are higher than the ones observed in our experiments (Fig. 1). Assuming a large sample length and using $k$ determined in this work, we used the KRFT model [26] to calculate the interface temperature as a function of time for 0.9 wt\% alloy. The solid line in Fig. 3b, which is for $\Delta=10$, matches with our experimental data. The planar front temperature, reported by TL [11] for this composition $\left(51.61^{\circ} \mathrm{C}\right)$, is obtained for $\Delta=$ 2, as shown by the dotted line in Fig. 3b. Thus, significant convection effects were present in their experiments. Note that the interface temperatures as function of time obtained with KRFT model for 


\section{ACCEPTED MANUSCRIPT}

$\Delta=2$ changes very slowly with time $\left(\approx 0.06^{\circ} \mathrm{C} /\right.$ day $)$ so that the interface is not "visibly" drifting, if the sample length is very large. This suggests why TL considered their reported $T_{s}$ to correspond to the solidus plateau.

The obtained solidus line was further confirmed through different sets of experiments. First, an alloy of $1.1 \mathrm{wt} \%$ camphor was heated above the eutectic temperature $T_{E}$ where initial microstructure was observed to consist of a solid primary dendrite with melted eutectic. The sample was held at this temperature for many hours and the sample was found to become completely solid. The sample was then heated and held at each temperature, and was found to remain solid until $48^{\circ} \mathrm{C}$. Some liquid region was observed when the sample was heated further to $48.5^{\circ} \mathrm{C}$ that did not disappear with time. This temperature should be close to the solidus temperature for this composition which is consistent with the value found for $0.9 \mathrm{wt} \%$ by directional solidification experiments. The solidus temperatures were also obtained by DSC, as shown in Figure 1, and these results are in good agreement with the results from our directional solidification experiments.

One alloy of composition 1.1 wt\% in camphor was additionally studied both by directional solidification and DSC experiments. The result obtained by DSC is presented in Figure 1, which corresponds to the solidus temperature of $48.95{ }^{\circ} \mathrm{C}$ or a partition coefficient $k=0.14 \pm 0.01$, which is consistent with the solidus temperature obtained in this study for lower concentrations. The directional solidification measurements for this experiment are not included in Figure 1 because at this growth speed the solid-liquid interface was cellular and not planar. The interface temperature in this case would refer to the cell tip temperature that reaches the steady state value at long times. However, for this nominal composition the steady-state temperature does not correspond to the solidus temperature because the interface was not planar until the end of solidification. If there is microstructures development, tips grow in the undercooled area towards the liquidus.

We now examine the isothermal annealing experiments by WHR [14] in which they measured liquid fraction as a function of temperature in SCN-1.1 wt\% camphor after isothermal annealing for 1 


\section{ACCEPTED MANUSCRIPT}

hour at each temperature. A liquid phase was shown to form and grow as round or elongated islands.

The equilibrium shape of a liquid droplet in this nearly isotropic surface energy system should be close to a sphere, which is not observed in the pictures presented [14]. The liquid droplets are larger than the sample thickness so that the contact angle at the glass-solid-liquid junction will distort the shape, in which case it is not possible to measure the volume fraction accurately. Also no systematic study of liquid volume fraction as a function of time was carried out to ensure that no change in volume fraction occurred after equilibrium condition is reached. We carried out isothermal annealing experiments in $\mathrm{SCN}-1.5$ and $3 \mathrm{wt} \%$ camphor alloys at $38{ }^{\circ} \mathrm{C}$ for many hours and the evolution of microstructure is shown in Figure 5 where both initial states are melted eutectic with solid primary dendrites. For 3 wt\%, after 2 hours, liquid droplets in solid are present, although the shapes of all the droplets are not spherical. The annealing was further carried out for 24 hours but significant coarsening is observed and droplets are not self-similar so that they do not represent equilibrium shapes within a solid. The droplet shapes are distorted from a nearly spherical shape due to the requirement of contact angle at the wall-interface junction, which can be very large if the sample thickness is very small. Since the measured volume fraction in this case will be significantly overestimated, the solidus composition will be underestimated. The isothermal annealing result in $1.5 \mathrm{wt} \%$ shows the presence of only the primary SCN solid phase at the end of the annealing whereas both the solid and the liquid phases should be present if the maximum solubility at the eutectic temperature is only $0.3 \mathrm{wt} \%$ camphor [14].

A more compelling argument against this maximum solubility is that directional solidification in 0.5 and 0.9 wt\% camphor should not give a steady-state single phase planar interface growth since the extrapolated solidus line will be below the eutectic temperature. In this case one should observe the formation of single phase that is followed by a transition to a eutectic structure. Since no eutectic is observed in these directional solidification experiments, the maximum solubility at the eutectic temperature must be higher than $0.9 \mathrm{wt} \%$ camphor. Our isothermal experiment in $1.5 \mathrm{wt} \%$ camphor 


\section{ACCEPTED MANUSCRIPT}

further show that the solubility of camphor at eutectic temperature must be higher than $1.5 \mathrm{wt} \%$.

Since solid and liquid phases are present just above eutectic temperature in the experiment with 3.0 wt $\%$ camphor, the solubility of camphor must be lower than $3.0 \mathrm{wt} \%$. So, the maximum solubility of camphor is expected to be between 1.5 and $3.0 \mathrm{wt} \%$ camphor.

\section{Conclusions}

Critical experiments are carried out to resolve the discrepancy present in the literature $[11,14]$ on the solidus line in the dilute limit of the succinonitrile - camphor phase diagram. In a transparent system, in which composition measurements in the solid are difficult, it is shown that directional solidification technique provides accurate values of the solidus temperature if it is ensured that no non-equilibrium effects are present at the interface and that experimental conditions are designed to make the effect of convection in the liquid negligible. Such conditions can be determined by interpreting experimental data using a boundary layer model of transient planar interface dynamics, which enables to assess quantitatively the effect of convection.

\section{Acknowledgments}

This research was achieved thanks to the support of NASA through Grants No. NNX16AB54G and NNX12AK54G, and CNES through the scientific project MISOL3D.

\section{References}

[1] W. Kurz, D.J. Fisher, Fundamentals of solidification, USA, 1998.

[2] A. Bogno, H. Nguyen-Thi, A. Buffet, G. Reinhart, B. Billia, N. Mangelinck-Noel, N. Bergeon, J. Baruchel, T. Schenk, Acta Mater., 59 (2011) 4356-4365.

[3] K.A. Jackson, J.D. Hunt, Acta Metall., 13 (1965) 1212-1215.

[4] H. Esaka, W. Kurz, J. Cryst. Growth, 72 (1985) 578-584.

[5] M.A. Eshelman, V. Seetharaman, R. Trivedi, Acta Metall., 36 (1988) 1165-1174.

[6] V. Seetharaman, M.A. Eshelman, R. Trivedi, Acta Metall., 36 (1988) 1175-1185. 


\section{ACCEPTED MANUSCRIPT}

[7] N. Bergeon, D. Tourret, L. Chen, J.M. Debierre, R. Guerin, A. Ramirez, B. Billia, A. Karma, R. Trivedi, Phys. Rev. Lett., 110 (2013) 6102.

[8] F.L. Mota, N. Bergeon, D. Tourret, A. Karma, R. Trivedi, B. Billia, Acta Mater., 85 (2015) 362-377.

[9] T. Sato, W. Kurz, K. Ikawa, Trans. J. Ins. Met., 28 (1987) 1012-1021.

[10] V.T. Witusiewicz, L. Sturz, U. Hecht, S. Rex, Acta Mater., 52 (2004) 4561-4571.

[11] J. Teng, S. Liu, J. Cryst. Growth, 290 (2006) 248-257.

[12] K. Kobayashi, Y. Seko, P.H. Shingu, J. Jpn. Inst. Met., 45 (1981) 647-651.

[13] T. Taenaka, H. Esaka, S. Mizoguchi, H. Kajioka, J. Jpn. Inst. Met., 52 (1988) 491-494.

[14] V.T. Witusiewicz, U. Hecht, S. Rex, J. Cryst. Growth, 375 (2013) 84-89.

[15] L.M. Fabietti, R. Trivedi, Metall. Trans. A, 22 (1991) 1249-1258.

[16] D. Camel, J.J. Favier, J. Cryst. Growth, 67 (1984) 42-56.

[17] D. Camel, J.J. Favier, J. Cryst. Growth, 67 (1984) 57-67.

[18] D. Camel, J.J. Favier, J Phys-Paris, 47 (1986) 1001-1014.

[19] J.C. LaCombe, J.L. Oudemool, M.B. Koss, L.T. Bushnell, M.E. Glicksman, J. Cryst. Growth, 173 (1997) 167-171.

[20] Q. Li, C. Beckermann, J. Cryst. Growth, 236 (2002) 482-498.

[21] L. Strutzenberg, Plane front dynamics and pattern formation in diffusion controlled directional solidification of alloys, Ames, USA, 2004.

[22] M.A. Chopra, M.E. Glicksman, N.B. Singh, Metall. Trans. A, 19 (1988) 3087-3096.

[23] R. Trivedi, H. Han, J.A. Sekhar, Microstructural Development in Interfiber Regions, in: P.Rohatgi (Ed.), Solidification of Metal - Matrix Composites, The Metallurgical Society of AIME, Warrendale, PA, 1990, pp. 23-37.

[24] B. Caroli, C. Caroli, B. Roulet, Instabilities of planar Solidification Fronts, in: C. Godrèche (Ed.), Solids Far From Equilibrium, Cambridge University Press, Cambridge, 1992, pp. 155-296.

[25] J.A. Warren, J.S. Langer, Phys. Rev. E, 47 (1993) 2702-2712.

[26] A. Karma, W.J. Rappel, B.C. Fuh, R. Trivedi, Metall. Mater. Trans. A, 29 (1998) 1457-1470.

[27] J.A. Burton, R.C. Prim, W.P. Slichter, J. Chem. Phys., 21 (1953) 1987-1991. 


\section{Figure 1}

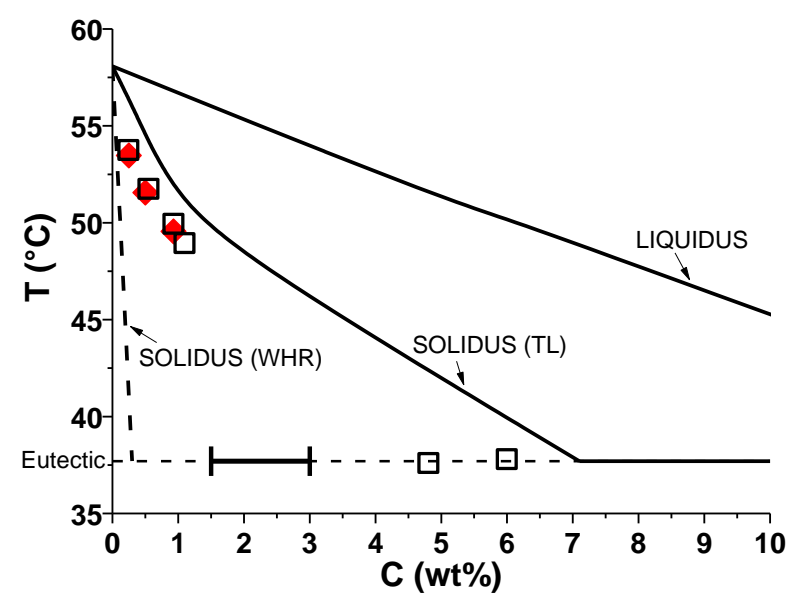

Figure 1 - Phase equilibria data for the binary alloy SCN-camphor: $\downarrow$, directional solidification measurements; $\square$, DSC measurements; -, TL [11]; - -, WHR [14]. The segment ( ]-[ ) represents the range where the solubility limit must be as determined by isothermal annealing. 


\section{ACCEPTED MANUSCRIPT}

\section{Figure 2}

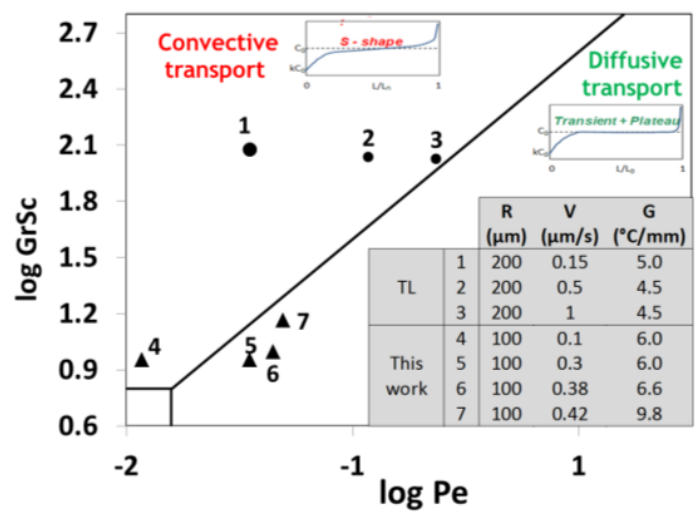

Figure 2 - Grashof-Schmidt number versus Peclet number diagram [16, 17] showing the regions of diffusive and convective growth. Experimental conditions used by TL [11] and those used in this work are shown in the inset table. 


\section{Figure 3}

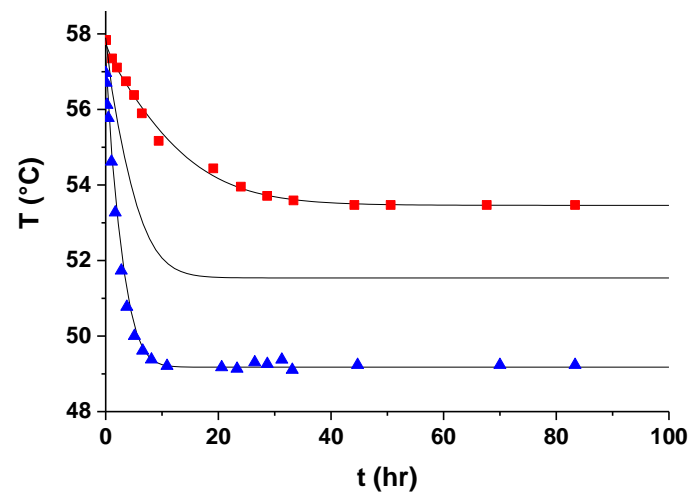

(a)

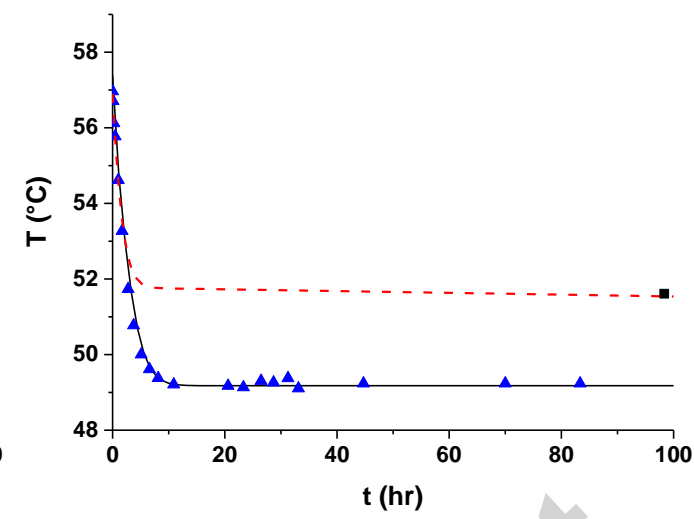

(b)

Figure 3 - (a) Interface temperature $(T)$ as function of time $(t)$ for different SCN-camphor alloys $0.24 \mathrm{wt} \%, 0.30 \mu \mathrm{m} / \mathrm{s}$ and $6.0 \mathrm{~K} / \mathrm{mm} ; \diamond, 0.5 \mathrm{wt} \%, 0.38 \mu \mathrm{m} / \mathrm{s}$ and $6.6^{\circ} \mathrm{C} / \mathrm{mm} ; \stackrel{\Delta}{\Delta}, 0.9 \mathrm{wt} \%$, $0.42 \mu \mathrm{m} / \mathrm{s}$ and $9.8 \mathrm{~K} / \mathrm{mm}$ ). The experimental results are compared to KRFT [26] model results $(-)$ with $\Delta \rightarrow \infty$. (b) Interface temperature as function of time for SCN-0.9wt\% camphor: ${ }^{\Lambda}$, this work; , TL [11] and KRFT model results. The solid line corresponds to $\Delta=$ 10 that fit our data, and the dotted line is for $\Delta=2$ that gives the interface temperature at long time that corresponds to the interface temperature value reported by TL [11]. 


\section{ACCEPTED MANUSCRIPT}

\section{Figure 4}

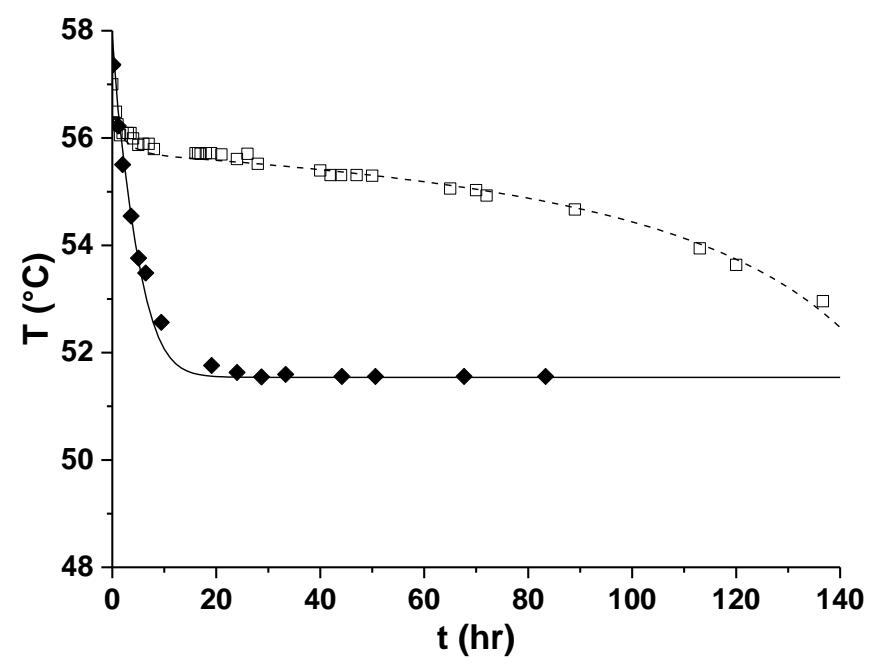

Figure 4 - Interface temperature for the SCN - 0.5 wt\% camphor alloy as a function of time for different experimental conditions: $\square, V=0.1 \mu \mathrm{m} / \mathrm{s}$ and $\mathrm{G}=7.1{ }^{\circ} \mathrm{C} / \mathrm{cm}$; and $\bullet, V=0.38$ $\mu \mathrm{m} / \mathrm{s}$ and $\mathrm{G}=6.6^{\circ} \mathrm{C} / \mathrm{mm}$. The experimental results are compared to KRFT [26] model results with $\Delta=2(--)$ and $\Delta \rightarrow \infty(-)$. 


\section{ACCEPTED MANUSCRIPT}

\section{Figure 5}
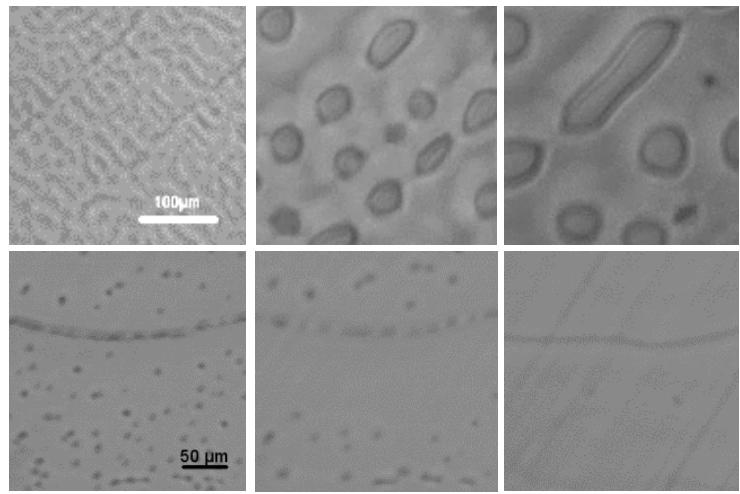

Figure 5 - Light microscopy images of the evolution of SCN-3 wt\% camphor $(a, b, c)$ and 1.5 wt\% camphor $(d, e, f)$ under isothermal conditions $\left(38^{\circ} \mathrm{C}\right)$ as a function of time $(t)$.

\section{Highlights}

- Critical experiments are carried out to resolve the dilemma in the succinonitrile-camphor phase diagram ;

- New measurements using thin-sample directional solidification experiments in purely diffusive transport;

- Complementary measurements using differential scanning calorimetry and isothermal annealing;

- Experimental results are further confirmed using a boundary layer model. 